Portland State University

PDXScholar

\title{
Supported Employment for Veterans with Traumatic Brain Injury: Provider Perspectives
}

\author{
Terri K. Pogoda \\ Center for Healthcare Organization and Implementation Research \\ Kathleen F. Carlson \\ Oregon Health and Science University \\ Katelyn E. Gormley \\ Center for Healthcare Organization and Implementation Research \\ Sandra Resnick \\ Yale University School of Medicine
}

Follow this and additional works at: https://pdxscholar.library.pdx.edu/sph_facpub

Part of the Trauma Commons, and the Vocational Rehabilitation Counseling Commons Let us know how access to this document benefits you.

\begin{abstract}
Citation Details
Pogoda TK, Carlson KF, Gormley KE, Resnick SG, Supported Employment for Veterans with Traumatic Brain Injury: Provider Perspectives, ARCHIVES OF PHYSICAL MEDICINE AND REHABILITATION (2017), doi: 10.1016/j.apmr.2017.06.029.
\end{abstract}

This Post-Print is brought to you for free and open access. It has been accepted for inclusion in OHSU-PSU School of Public Health Faculty Publications and Presentations by an authorized administrator of PDXScholar. Please contact us if we can make this document more accessible: pdxscholar@pdx.edu. 


\section{Accepted Manuscript}

Supported Employment for Veterans with Traumatic Brain Injury: Provider Perspectives

Terri K. Pogoda, PhD, Kathleen F. Carlson, PhD, Katelyn E. Gormley, MPH, Sandra G. Resnick, PhD

PII: S0003-9993(17)30525-7

DOI: 10.1016/j.apmr.2017.06.029

Reference: YAPMR 56972

To appear in: ARCHIVES OF PHYSICAL MEDICINE AND REHABILITATION

Received Date: 11 January 2017

Revised Date: 22 May 2017

Accepted Date: 29 June 2017

Please cite this article as: Pogoda TK, Carlson KF, Gormley KE, Resnick SG, Supported Employment for Veterans with Traumatic Brain Injury: Provider Perspectives, ARCHIVES OF PHYSICAL MEDICINE AND REHABILITATION (2017), doi: 10.1016/j.apmr.2017.06.029.

This is a PDF file of an unedited manuscript that has been accepted for publication. As a service to our customers we are providing this early version of the manuscript. The manuscript will undergo copyediting, typesetting, and review of the resulting proof before it is published in its final form. Please note that during the production process errors may be discovered which could affect the content, and all legal disclaimers that apply to the journal pertain. 
1 Running Head: Providing Supported Employment to Veterans with TBI

2

3

4

5

6

7

8

Supported Employment for Veterans with Traumatic Brain Injury: Provider Perspectives Terri K. Pogoda, $\mathrm{PhD}^{1,2}$; Kathleen F. Carlson, $\mathrm{PhD}^{3,4}$; Katelyn E. Gormley, $\mathrm{MPH}^{1}$; Sandra G. Resnick, $\mathrm{PhD}^{5,6}$

${ }^{1}$ Center for Healthcare Organization and Implementation Research, VA Boston Healthcare System, Boston, MA

${ }^{2}$ Department of Health Law, Policy \& Management, Boston University School of Public Health, Boston, MA

${ }^{3}$ Center to Improve Veteran Involvement in Care and National Center for Rehabilitative Auditory Research, VA Portland Health Care System, Portland, OR

${ }^{4}$ Oregon Health and Science University-Portland State University School of Public Health, Portland, OR

${ }^{5}$ New England Mental Illness, Research and Clinical Center, VA Connecticut Healthcare System, West Haven, CT

${ }^{6}$ Department of Psychiatry, Yale University School of Medicine, New Haven, CT

Corresponding author:

Terri K. Pogoda, $\mathrm{PhD}$

Center for Healthcare Organization and Implementation Research

VA Boston Healthcare System

Building 9, Office 218

150 South Huntington Avenue (152M)

Boston, MA 02130

Phone: 857-364-2626 
Fax: 857-364-6140

Email: terri.pogoda@va.gov

Acknowledgements. The views expressed in this article are the authors' and do not necessarily represent the views of the Department of Veterans Affairs or the United States Government. This work was supported by the VA Health Services Research \& Development Center for Healthcare Organization and Implementation Research, which provided financial support only. The authors wish to thank Shana Bakken, PhD and Joseph Carlomagno, MEd for their contributions to and support of this research.

\section{Disclosures: None.}

Parts of this research were presented at the 2015 Annual Research Meeting of AcademyHealth, Minneapolis, MN (June 15, 2015); National Meeting of VA Health Services Research and Development Service, Philadelphia, PA (July 9, 2015); 2015 VA Office of Research \& Development TBI State-of-the-Art Conference, Washington, DC (August 24, 2015); and the 2016 Defense Centers of Excellence for Psychological Health and Traumatic Brain Injury Summit, Falls Church, VA (September 13, 2016). 
1

2

3 Objective: In 2006, 13 sites were provided with one-time pilot funding to provide supported Supported Employment for Veterans with Traumatic Brain Injury: Provider Perspectives

Abstract
4

5

6

7

8

9 employment (SE) to Veterans with traumatic brain injury (TBI) history. In 2014, we surveyed SE providers at pilot and non-pilot sites that did not receive this funding. Our objectives were to identify any pilot and non-pilot site differences regarding current: (1) provision of SE to Veterans with TBI; (2) staffing and communication between the SE and polytrauma/TBI teams; and (3) provider perceptions on facilitators and barriers to providing, and suggestions for improving, SE.

Setting: Veterans Health Administration (VHA) SE programs.

Design: Mixed methods cross-sectional survey study.

Participants: Providers included a total of 54 SE supervisors and 90 vocational rehabilitation specialists (VRSs).

Interventions: Not applicable.

Main Outcome Measures: Web-based surveys of forced-choice and open-ended items included questions on SE team characteristics, communication with polytrauma/TBI teams, and experiences with providing SE to Veterans with TBI history.

Results: SE was provided to Veterans with TBI at $100 \%$ of pilot and 59.2\% of non-pilot sites (p $=.09$ ). However, VRSs at pilot sites reported that communication with the polytrauma/TBI team about SE referrals was more frequent than at non-pilot sites $(\mathrm{p}=.003)$. In open-ended items, suggestions for improving SE were similar across pilot and non-pilot sites, and included 
increasing staffing for VRSs and case management, enhancing communication and education between SE and polytrauma/TBI teams, and expanding the scope of the SE program so that eligibility is based on employment support need, rather than diagnosis.

Conclusions: These findings may contribute to an evidence base that informs SE research and clinical directions on service provision, resource allocation, team integration efforts, and outreach to Veterans with TBI who have employment support needs.

Keywords: Supported Employment, Traumatic Brain Injury; Veterans; Interdisciplinary Health Team; Community Integration

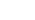


41

Abbreviations

42

43

Compensated Work Therapy (CWT)

44

45

Individual Placement and Support (IPS) model of Supported Employment (SE)

Institutional Review Board (IRB)

47 Polytrauma Network Site (PNS)

48

Polytrauma Support Clinic Team (PSCT)

49

Polytrauma Point of Contact (PPOC)

50

Polytrauma/TBI System of Care (PSC)

51

Posttraumatic stress disorder (PTSD)

52

Severe mental illness (SMI)

53 Therapeutic and Supported Employment Services (TSES)

54

Traumatic brain injury (TBI)

55

Department of Veterans Affairs (VA)

56

Veterans Health Administration (VHA)

57

Vocational rehabilitation specialist (VRS) 
More than 2.7 million U.S. service members have been deployed in support of the Iraq and Afghanistan wars. ${ }^{1}$ As many Veterans return to civilian life with service-related physical and psychological injuries, including traumatic brain injury (TBI), it is critical that healthcare systems are adequately resourced to address their health and psychosocial needs. ${ }^{2}$ Frontline clinicians and healthcare managers can provide essential macro-level perspectives on patient health service needs. ${ }^{3-7}$ This key stakeholder input allows for successes to be documented and shared, but is also important for identifying gaps in care. A methodology that identifies facilitators and barriers to service provision is important for informing recommendations on future implementation efforts that address healthcare concerns. ${ }^{3,8}$ Here, we report the results of a survey of Veterans Health Administration (VHA) Compensated Work Therapy (CWT) program supervisors and frontline vocational rehabilitation specialists (VRSs) about their experiences with and perceptions of providing the evidence-based Individual Placement and Support (IPS) model of Supported Employment ${ }^{9}$ (hereafter referred to as SE) to Veterans with TBI.

VHA provides a range of vocational rehabilitation services through its Therapeutic and Supported Employment Services (TSES) CWT program. In fiscal year 2005, SE for individuals with severe mental illness (SMI) was implemented VHA-wide. ${ }^{10}$ Policy allowed up to $25 \%$ of an SE caseload to include Veterans without SMI but who had intense employment support needs. SE is designed for individuals unable to work independently without intense intervention. Various models of supported employment, including the IPS model of SE, have been evaluated in civilian populations and shown to be effective for those with intellectual/developmental disabilities, physical disabilities, and moderate/severe TBI history. ${ }^{11,12}$ SE's core principles include no pre-requisite vocational training, rapid job searches for competitive work that matches the individual's interests, long-term workplace support as needed, and integration between the 
SE and clinical treatment teams so that health and employment-related issues can be addressed in tandem. ${ }^{9,13}$ A significant minority of Iraq and Afghanistan war Veterans using VHA services have TBI history and are unemployed. ${ }^{14}$ However, among those with a history of TBI, a substantial proportion may have intense employment support needs. In a national survey of Veterans with TBI, $45 \%$ reported unemployment. In this same survey, $42 \%$ reported at least moderate interest in SE. ${ }^{15}$ Providing SE to these Veterans, many of whom are in their prime working years ${ }^{14}$ could positively impact their long-term employment success.

In the U.S. civilian population, approximately 2.5 million individuals sustain a TBI annually, ${ }^{16}$ and since 2000 , more than 360,000 TBIs have been reported in U.S. military service members. ${ }^{17}$ In an analysis of more than 600,000 Iraq and Afghanistan war Veterans accessing VHA services between 2009 and 2011, 9.6\% had a TBI diagnosis. ${ }^{18}$ For both civilians ${ }^{19}$ and recent U.S. service members,${ }^{20}$ at least $75 \%$ of diagnosed cases are classified as mild TBI.

Workforce participation is considered a significant indicator of recovery and has been closely studied in those who sustained TBI. ${ }^{21-28}$ The return to work rate following TBI varies widely ${ }^{29,30}$ and is associated with various demographic, injury-related, and post-injury rehabilitation factors, including use of vocational rehabilitation services. ${ }^{31-35}$ For many civilians, return to pre-injury levels of functioning following mild TBI usually occurs within 3 to $12^{36}$ months or sooner, ${ }^{37,38}$ although up to $20 \%{ }^{39}$ continue to experience a range of cognitive, emotional, and physical symptoms ${ }^{40}$ years after the injury that impact function. For those who served in the Iraq and Afghanistan wars, recovery from mild TBI is difficult to measure and is confounded by such factors as reporting delays ${ }^{41}$ and comorbid conditions like posttraumatic stress disorder (PTSD), ${ }^{18,42,43}$ depression, and substance use,${ }^{44}$ which may complicate evaluation and rehabilitation. ${ }^{45}$ 
VHA's Polytrauma/TBI System of Care (PSC) was developed to address the multiple healthcare needs of Iraq and Afghanistan war Veterans with TBI and comorbid conditions. Its outpatient services include 23 regional Polytrauma Network Sites (PNS), 87 Polytrauma Support Clinic Teams (PSCT) that are more geographically dispersed, and 39 Polytrauma Points of Contact (PPOC) that do not have polytrauma/TBI rehabilitation teams but can make referrals for appropriate care. ${ }^{46,47}$ Interdisciplinary polytrauma/TBI rehabilitation teams include physiatrists, psychologists, and case managers. ${ }^{48}$ Vocational rehabilitation specialists (VRSs) are not typically core team members, but may be co-located in the same medical center or available for referral. In 2006, VHA TSES provided 13 CWT programs with one-time funding for that fiscal year for a dedicated VRS to provide SE to Veterans with TBI history. At most pilot sites there was also funding for a psychologist to facilitate integration between vocational rehabilitation and clinical providers. Due to limited resources, there was no contemporaneous evaluation of this implementation. In 2014, we followed up with SE supervisors and VRSs from the 13 pilot sites and their counterparts at other (non-pilot) sites that did not receive this specialized funding. This study's objectives were to identify any differences between pilot and non-pilot sites with regard to providing SE to Veterans with TBI; staffing and communication between the SE and polytrauma/TBI teams; and provider perceptions on facilitators and barriers to, and suggestions for, improving SE for this Veteran population. We hypothesized that compared to non-pilot sites, pilot sites would: (1) have a higher rate of providing SE to Veterans with TBI history, (2) report better interactions between the SE and polytrauma/TBI teams, and (3) experience fewer challenges with providing SE to Veterans with TBI history. 
Design. This was a mixed methods cross-sectional survey study with forced choice and openended questions.

Participants. Target participants were identified through VHA administrative records, and included SE program supervisors (pilot sites: $\mathrm{n}=13$; non-pilot sites: $\mathrm{n}=133$ ) and VRSs (pilot sites: $\mathrm{n}=90$; non-pilot sites: $\mathrm{n}=159$ ). SE providers could not be identified at 2 of the 152 Department of Veterans Affairs (VA) medical centers, and therefore these 2 sites were excluded from participating.

Procedure. The Research and Development Committees and/or human subjects Institutional Review Boards (IRBs) of the research team investigators approved all procedures. Prior to recruitment, we notified 150 VA medical center directors about the study. Of these, four prohibited the survey from proceeding locally because of privacy concerns or lack of local IRB guidance, and were subsequently excluded. Using a modified Dillman method for mailing timelines, ${ }^{49}$ in August 2014 we emailed invitations to participate in a web-based survey to SE providers at the remaining 146 sites. The survey was programmed in and administered using Verint Enterprise Feedback Management software version 6.5 (Melville, NY), which securely captured responses within the VA firewall.

Survey questions differed by participant type. For forced-choice items, supervisors were asked to provide information on broader program-level issues, such as which clinical populations their SE program served, and current and ideal full-time employee equivalent (FTEE) hours dedicated to providing SE to Veterans with TBI history. Questions for SE VRSs focused on field-level experiences, such as working with the site's polytrauma/TBI clinic team (yes/no), communication frequency with the polytrauma/TBI clinic team about SE referrals on a 1 (never) 
to 9 (daily or almost daily) Likert-type scale, and perceived helpfulness in working with the polytrauma/TBI clinic team on a 1 (not at all) to 5 (extremely) Likert-type scale. The software had automated skip patterns so that participants did not respond to questions that previous responses indicated were not applicable. For example, participants at sites without a polytrauma/TBI team (PPOC) were not presented with questions about their interactions with them.

Open-ended questions asked respondents to: list their ideal SE team composition (supervisors only), describe their experiences working with Veterans and the local polytrauma/TBI clinic team (VRSs only), identify training they have received (VRSs only), and suggest program improvements (supervisors and VRSs).

\section{Statistical Analysis}

Means, standard deviations, percentages, and proportions were used to describe the quantitative outcome variables. Continuous outcomes were compared using independent and pairwise t-tests. For categorical data, we used chi-square test for independence, and Fisher's Exact Test (one-sided) when the statistical assumptions for chi-square were not met. We also tested VA medical center characteristics, including pilot site status, region of country (West, Midwest, South, Northeast), and outpatient PSC level (PNS, PSCT, PPOC) to identify any differences between responders and non-responders. Analyses were performed with IBM SPSS Statistics v20..$^{50}$

\section{Qualitative Analysis}

Open-ended responses were coded with NVivo v10. ${ }^{51}$ A priori constructs focused on general experiences providing SE to Veterans with TBI history; working with polytrauma/TBI clinic providers; and facilitators, challenges, and suggested improvements for providing SE to 
these Veterans. Any new themes that emerged were coded. Inter-rater reliability between two team members (TKP, KEG) was established using a "check-coding" process. ${ }^{52}$ Open-ended responses were coded independently for 10 respondents, and initial reliability estimates (agreements as a proportion of agreements plus disagreements) were at least $85 \%$. Consensus was reached after discussing areas of initial disagreement. Additional open-ended responses from 5 different participants were then independently coded by both team members, maintaining a stable level of percent agreement of $\geq .90$. Finally, the remaining open-ended responses were coded independently.

\section{Quantitative.}

Response rate. Response rate for SE supervisors was similar across pilot $(5 / 13 ; 38.5 \%)$ and nonpilot $(49 / 133 ; 36.8 \%)$ sites $(\mathrm{p}=.51)$, and was not independently associated with country region $(\mathrm{p}=.81)$, or PSC level $(\mathrm{p}=.87)$. For VRSs, the response rate between the pilot $(14 / 40 ; 35.0 \%)$ and non-pilot $(76 / 209 ; 36.4 \%)$ sites was also comparable $(\mathrm{p}=.87)$, and did not vary by country region $(\mathrm{p}=.70)$ or PSC level $(\mathrm{p}=.97)$.

SE Supervisors. Length of time supervising the SE program was comparable across pilot and non-pilot sites (Table 1). The percentage of sites providing SE to Veterans with TBI history was higher among pilot (100\%) than non-pilot (59\%) sites, although this result did not reach statistical significance $(\mathrm{p}=.09)$. Across sites, supervisors reported comparable VRS FTEE hours dedicated to serving Veterans with TBI history. Notably, there was more than a twofold gap in the current versus perceived ideal FTEE hours for providing SE to Veterans with TBI history at 
both pilot $(\mathrm{M}=.70, \mathrm{SD}=.45$ vs. $\mathrm{M}=1.80, \mathrm{SD}=.45, \mathrm{p}<.02)$ and non-pilot $(\mathrm{M}=.76, \mathrm{SD}=.87$ vs. $\mathrm{M}=1.67, \mathrm{SD}=.93, \mathrm{p}<.0001)$ sites.

SE VRSs. Length of time working in the SE program was comparable across pilot and non-pilot sites. Respondents across sites were similarly divided in their perceptions on how providing SE to Veterans with TBI history compared to Veterans with other conditions, with approximately half endorsing that it was about the same to easier, and half stating that it was more difficult. After excluding participants from PPOCs, there was no statistically significant difference in percentages of pilot and non-pilot sites that worked with the polytrauma/TBI teams. Among sites that reported working with the polytrauma/TBI team, communication between the SE and polytrauma/TBI clinic teams about SE referrals was reported to be more frequent among pilot site VRSs compared to what was reported from non-pilot site VRSs. Despite communication frequency differences, across sites the VRSs perceived the polytrauma/TBI teams to be moderately to very helpful when they worked together.

\section{Qualitative}

Supervisors. SE program supervisors were asked to list which disciplines they would add to their SE teams to further support the needs of Veterans with TBI history. Because of similarities, responses are collapsed across pilot and non-pilot sites (Table 2). The three most frequently identified disciplines were: peer support specialists, case managers/social workers, and job developers that were separate from VRSs. Others included mental/behavioral health professionals, medical providers, and other rehabilitation providers.

SE supervisor perspectives on how to improve SE services for Veterans with TBI history may be seen in Table 3. The most frequent suggestion for program improvement was to increase VRS FTEE dedicated to serving Veterans with TBI history. Some supervisors were concerned 
that employment was not prioritized during the recovery process and recommended that vocational rehabilitation be discussed as part of rehabilitation treatment planning. They also suggested that SE eligibility be based on level of employment support need, rather than diagnosis. Finally, although employment is an obvious goal of vocational rehabilitation, some supervisors were concerned that the CWT program was too focused on jobs, rather than careers, and suggested that continuing education be considered an important gateway to future employment.

SE VRSs. Table 4 illustrates content domains and exemplar quotes by VRSs regarding their experiences with providing SE to Veterans with TBI history. The most noted challenge in working with these clients was their co-occurring cognitive and behavioral conditions, especially problems with memory and anger, which require more intense workplace support. At the facility level, perceived facilitators of SE success were leadership providing administrative resources; clinicians taking a team-based approach to care, which was further supported by VRSs attending weekly meetings and having ongoing communication with the team; supportive community employers; and family and peer support involvement. Reported barriers to providing SE included leadership not wanting to expand it to other clinical populations, like those with TBI; clinicians not valuing employment or understanding the SE model, and the case management needs of Veterans not being met.
Discussion
There was strong support by SE supervisors and VRSs that SE would be a positive and integral support for readjustment to civilian life for Veterans with TBI who have intense employment support needs. Across pilot and non-pilot sites, SE supervisors advocated for an 
expansion of services for Veterans with TBI history on multiple levels: increased staffing for VRSs and other Veteran supports (e.g., peer support specialists, case managers); emphasizing the importance of employment during rehabilitation treatment planning; extending SE eligibility to those with functional limitations, irrespective of diagnosis; and broadening SE services to include support for continuing education. We note that SE focuses on competitive employment, rather than education. It de-emphasizes pre-vocational training, and promotes working with Veterans to find jobs that match their current skill level and interests. However, our findings are consistent with the growing literature on supported education, ${ }^{53,54}$ which can assist returning Veterans with TBI with educational pursuits.

A recent survey of Veterans with TBI who use VHA, conducted in parallel to the current one, demonstrated a high rate of unemployment and an interest in receiving SE. ${ }^{15}$ Together, these studies suggest that offering SE to Veterans with TBI would be well-received by both patients and SE providers. These findings are also consistent with earlier studies of provider perspectives. In interviews about the rehabilitation needs of Veterans with polytrauma/TBI, VHA providers reported that those with jobs worry about maintaining them as they cope with memory loss, ${ }^{4}$ and a "need for more and tailored vocational services" (p. 708) ${ }^{7}$ for these Veterans. Difficulty with vocational and clinical team integration, the need for provider education, and lack of resources have also been described in smaller, time-limited studies that implemented SE for Veterans with spinal cord injury ${ }^{3}$ and SMI. ${ }^{5}$ Addressing Veteran vocational rehabilitation needs and implementing SE remain ongoing challenges.

SE supervisors at nearly $60 \%$ and $100 \%$ of responding non-pilot and pilot sites, respectively, reported that their SE programs currently served Veterans with TBI. This was more prevalent than we had anticipated, since Veterans with SMI are the intended recipients of most 
SE services. Our hypothesis that a higher rate of pilot sites would provide SE to Veterans with TBI history was not supported by statistical significance testing; however, the difference in percentages suggests a trend that pilot sites are more likely to provide SE to Veterans with TBI history.

Among sites that had polytrauma/TBI teams, a similar percentage of VRSs from pilot and non-pilot sites indicated that they worked with these clinicians. This may reflect greater VHAwide awareness of vocational rehabilitation needs for Veterans with TBI or a growing trend of interdisciplinary collaboration for this clinical population. Nonetheless, VRSs at pilot sites reported more frequent communication about SE referrals than VRSs at non-pilot sites. Thus, the pilot funding may have been a facilitating mechanism to develop and sustain communications between the SE and polytrauma/TBI teams that continued after the funding ended. However, it is not possible to parse out cause and effect in this cross-sectional study; it is also possible that sites that received pilot funding were already coordinating care between their polytrauma/TBI and SE teams or were better positioned to integrate care than sites that did not receive pilot funding.

Despite this, these findings are consistent with our hypothesis that better interactions between the SE and clinical teams would be associated with previous funding support. ${ }^{13}$ Our third hypothesis that pilot sites would have fewer current SE challenges was not supported. Open-ended responses revealed concerns that there was not a shared knowledge-base about SE program principles and education on TBI, perceptions that case management needs were not being met (e.g., by the polytrauma/TBI team), and perceived weak management support to expand SE to Veterans with TBI history.

The majority of Iraq and Afghanistan war Veterans with TBI have co-occurring psychiatric diagnoses, pain, and other symptoms, ${ }^{14,18,55}$ which underscores the importance of 
interdisciplinary treatment. Unlike other federal, state, or local agencies in which supported employment is compromised by a fragmented system wherein employment and clinical providers may work in different healthcare settings,,${ }^{9,56}$ the VHA provides a national infrastructure for SE and polytrauma/TBI programs to co-exist within many VA medical centers or regional VA healthcare systems. The extent to which employment and clinical providers integrate, rather than work in parallel, is modifiable ${ }^{56}$ but may be constrained by local resources. Without adequate supports, local implementation practices can drift from the SE model. ${ }^{5,57}$ Historically, VHA SE implementation efforts have included technical assistance and on-site monitoring by SE experts who conduct thorough reviews (e.g., SE providers, client, and employer interviews), evaluate each site's SE model adherence, and report results to local leadership to facilitate engagement. ${ }^{10,58,59}$ Any future implementation efforts to provide SE to Veterans with TBI will benefit from a small-scale demonstration study that incorporates these elements, in addition to systematic and contemporaneous documentation and assessment of facilitators and barriers. Lessons learned from that effort can be used to tailor strategies to maximize successful implementation in any larger-scale rollout. ${ }^{8}$

In 2016, the VHA TSES program announced a Transformation Plan that includes a focus on competitive employment services, including SE, and a new program called Community Based Employment Services, an evidence-informed practice that follows SE principles but is intended for those not requiring the employment support intensity that is offered through SE. These program shifts may provide additional opportunities for Veterans with TBI history to reach their vocational potential.

Study Limitations 
The study is limited by several factors, including its cross-sectional design which precludes interpretations about cause and effect. Survey data were captured eight years after the pilot funding. Without a detailed accounting of each site's SE implementation efforts, we cannot determine whether the snapshot represents an iteration, new development, sustainment, or devolvement in process. We also assumed that sites that reported providing SE were providing the IPS model of SE, but we could not verify the extent of SE implementation fidelity. ${ }^{57}$ for Veterans with TBI history would be enhanced by ascertaining these patient characteristics.

\section{Conclusions}

SE supervisor and VRS experiences on providing SE to Veterans with TBI discussed here complement the vocational rehabilitation needs, interests, and service use described by Veterans with TBI history in a parallel survey effort. ${ }^{15}$ Together, these findings can contribute to an evidence base that informs VHA research and clinical considerations of service provision, resource allocation, team integration efforts, and outreach to Veterans with intense employment support needs. 
1. Epidemiology Program P-DHG, Office of Public Health, Veterans Health Administration, Department of Veterans Affairs. Analysis of VA Health Care Utilization among Operation Enduring Freedom, Operation Iraqi Freedom, and Operation New Dawn Veterans, from 1st Qtr FY 2002 through 2nd Qtr FY 2015. 2015; http://www.publichealth.va.gov/docs/epidemiology/healthcare-utilization-report-fy2015-

2. Amara J, Iverson KM, Krengel M, Pogoda TK, Hendricks A. Anticipating the traumatic qtr2.pdf. Accessed May 1, 2017.

3. Cotner BA, Ottomanelli L, O'Connor DR, Trainor JK. Provider-identified barriers and facilitators to implementing a supported employment program in spinal cord injury. Disabil Rehabil. 2017:1-7.

4. Friedemann-Sanchez G, Sayer NA, Pickett T. Provider perspectives on rehabilitation of patients with polytrauma. Archives of physical medicine and rehabilitation. 2008;89(1):171-178.

5. Pogoda TK, Cramer IE, Rosenheck RA, Resnick SG. Qualitative analysis of barriers to implementation of supported employment in the Department of Veterans Affairs. Psychiatric services. 2011;62(11):1289-1295.

6. Sayer NA, Cifu DX, McNamee S, et al. Rehabilitation needs of combat-injured service members admitted to the VA Polytrauma Rehabilitation Centers: the role of PM\&R in the 
care of wounded warriors. $P M \& R$ : the journal of injury, function, and rehabilitation.

355

356

357

358 2009;1(1):23-28.

7. Sayer NA, Rettmann NA, Carlson KF, et al. Veterans with history of mild traumatic brain injury and posttraumatic stress disorder: challenges from provider perspective. Journal of rehabilitation research and development. 2009;46(6):703-716.

8. Powell BJ, Waltz TJ, Chinman MJ, et al. A refined compilation of implementation strategies: results from the Expert Recommendations for Implementing Change (ERIC) project. Implement Sci. 2015;10:21.

9. Drake RE, Bond GR, Becker DR. Individual placement and support: an evidence-based approach to supported employment. Oxford University Press; 2012.

10. Resnick SG, Rosenheck R. Dissemination of supported employment in Department of Veterans Affairs. Journal of rehabilitation research and development. 2007;44(6):867877.

11. Wehman P, Revell G, Kregel J, Act D. Supported employment: A decade of rapid growth. Supported employment research: Expanding competitive employment opportunities for persons with significant disabilities. 1997:1.

12. Wehman PH, Revell WG, Kregel J, Kreutzer JS, Callahan M, Banks PD. Supported employment: an alternative model for vocational rehabilitation of persons with severe neurologic, psychiatric, or physical disability. Archives of physical medicine and rehabilitation. 1991;72(2):101-105.

13. Bond GR, Drake RE. Making the case for IPS supported employment. Administration and policy in mental health. 2014;41(1):69-73. 
14. Pogoda TK, Stolzmann KL, Iverson KM, et al. Associations Between Traumatic Brain Injury, Suspected Psychiatric Conditions, and Unemployment in Operation Enduring Freedom/Operation Iraqi Freedom Veterans. J Head Trauma Rehabil. 2016;31(3):191203.

15. Carlson K, Pogoda T, Gilbert T, et al. Supported Employment for Veterans with Traumatic Brain Injury: Patient Perspectives. Arch Phys Med Rehabilunder review, this issue.

16. Centers for Disease Control and Prevention NCfIPaC, Division of Unintentional Injury Prevention. Injury Prevention \& Control: Traumatic Brain Injury. 2016; https://www.cdc.gov/traumaticbraininjury/get_the_facts.html. Accessed December 16, 2016.

17. Defense and Veterans Brain Injury Center. DoD Numbers for Traumatic Brain Injury. 2016; http://dvbic.dcoe.mil/files/tbi-numbers/DoD-TBI-Worldwide-Totals_20002016_Q1-Q2_Aug-12-2016_v1.0_2016-09-20.pdf. Accessed Oct 19, 2016.

18. Cifu DX, Taylor BC, Carne WF, et al. Traumatic brain injury, posttraumatic stress disorder, and pain diagnoses in OIF/OEF/OND Veterans. Journal of rehabilitation research and development. 2013;50(9):1169-1176.

19. Centers for Disease Control and Prevention. The Report to Congress on Mild Traumatic Brain Injury in the United States: Steps to Prevent a Serious Public Health Problem. Atlanta: Centers for Disease Control and Prevention;2003.

20. Defense and Veterans Brain Injury Center. DoD Worldwide Numbers for TBI. 2017; Available from: http://dvbic.dcoe.mil/dod-worldwide-numbers-tbi. Accessed 2017, April 17. 
21. Wehman P, West M, Fry R, et al. Effect of supported employment on the vocational outcomes of persons with traumatic brain injury. Journal of applied behavior analysis. 1989;22(4):395-405.

22. Wehman P, Kregel J, West M, Cifu D. Return to work for patients with traumatic brain injury. Analysis of costs. American journal of physical medicine \& rehabilitation. 1994;73(4):280-282.

23. Chesnut RM, Carney N, Maynard H, Mann NC, Patterson P, Helfand M. Summary report: evidence for the effectiveness of rehabilitation for persons with traumatic brain injury. J Head Trauma Rehabil. 1999;14(2):176-188.

24. Sherer M, Novack TA, Sander AM, Struchen MA, Alderson A, Thompson RN. Neuropsychological assessment and employment outcome after traumatic brain injury: a review. The Clinical neuropsychologist. 2002;16(2):157-178.

25. Wehman P, Kregel J, Keyser-Marcus L, et al. Supported employment for persons with traumatic brain injury: a preliminary investigation of long-term follow-up costs and program efficiency. Archives of physical medicine and rehabilitation. 2003;84(2):192196.

26. Twamley EW, Baker DG, Norman SB, Pittman J, Lohr JB, Resnick SG. Veterans health administration vocational services for Operation Iraqi Freedom/Operation Enduring Freedom veterans with mental health conditions. Journal of rehabilitation research and development. 2013;50(5):663-670.

27. Twamley EW, Jak AJ, Delis DC, Bondi MW, Lohr JB. Cognitive Symptom Management and Rehabilitation Therapy (CogSMART) for veterans with traumatic brain injury: pilot 
randomized controlled trial. Journal of rehabilitation research and development. 2014;51(1):59-70.

28. O'Connor MK, Mueller L, Kwon E, et al. Enhanced vocational rehabilitation for Veterans with mild traumatic brain injury and mental illness: Pilot study. Journal of rehabilitation research and development. 2016;53(3):307-320.

29. Shames J, Treger I, Ring H, Giaquinto S. Return to work following traumatic brain injury: trends and challenges. Disability and Rehabilitation. 2007;29(17):1387-1395.

30. Yasuda S, Wehman P, Targett P, Cifu D, West M. Return to work for persons with traumatic brain injury. American journal of physical medicine \& rehabilitation. 2001;80(11):852-864.

31. Dillahunt-Aspillaga C, Nakase-Richardson R, Hart T, et al. Predictors of Employment Outcomes in Veterans With Traumatic Brain Injury: A VA Traumatic Brain Injury Model Systems Study. J Head Trauma Rehabil. 2017.

32. Doctor JN, Castro J, Temkin NR, Fraser RT, Machamer JE, Dikmen SS. Workers' risk of unemployment after traumatic brain injury: a normed comparison. Journal of the International Neuropsychological Society : JINS. 2005;11(6):747-752.

33. Keyser-Marcus LA, Bricout JC, Wehman P, et al. Acute predictors of return to employment after traumatic brain injury: a longitudinal follow-up. Archives of physical medicine and rehabilitation. 2002;83(5):635-641.

34. Ownsworth T, McKenna K. Investigation of factors related to employment outcome following traumatic brain injury: a critical review and conceptual model. Disabil Rehabil. 2004;26(13):765-783. 
35. Ponsford J. Factors contributing to outcome following traumatic brain injury. NeuroRehabilitation. 2013;32(4):803-815.

36. Carroll LJ, Cassidy JD, Peloso PM, et al. Prognosis for mild traumatic brain injury: results of the WHO Collaborating Centre Task Force on Mild Traumatic Brain Injury. $J$ Rehabil Med. 2004(43 Suppl):84-105.

37. Iverson GL. Outcome from mild traumatic brain injury. Current opinion in psychiatry. 2005;18(3):301-317.

38. McCrea M, Guskiewicz KM, Marshall SW, et al. Acute effects and recovery time following concussion in collegiate football players: the NCAA Concussion Study. JAMA : the journal of the American Medical Association. 2003;290(19):2556-2563.

39. Ruff R. Two decades of advances in understanding of mild traumatic brain injury. The Journal of head trauma rehabilitation. 2005;20(1):5-18.

40. Meterko M, Baker E, Stolzmann KL, Hendricks AM, Cicerone KD, Lew HL. Psychometric Assessment of the Neurobehavioral Symptom Inventory-22: The Structure of Persistent Postconcussive Symptoms Following Deployment-Related Mild Traumatic Brain Injury Among Veterans. J Head Trauma Rehabil. 2012;27 (1):55-62.

41. Schwab KA, Ivins B, Cramer G, et al. Screening for traumatic brain injury in troops returning from deployment in Afghanistan and Iraq: initial investigation of the usefulness of a short screening tool for traumatic brain injury. J Head Trauma Rehabil. 2007;22(6):377-389.

42. Carlson KF, Kehle SM, Meis LA, et al. Prevalence, assessment, and treatment of mild traumatic brain injury and posttraumatic stress disorder: a systematic review of the evidence. J Head Trauma Rehabil. 2011;26(2):103-115. 
43. Stein MB, McAllister TW. Exploring the convergence of posttraumatic stress disorder and mild traumatic brain injury. The American journal of psychiatry. 2009;166(7):768776.

44. Halbauer JD, Ashford JW, Zeitzer JM, Adamson MM, Lew HL, Yesavage JA. Neuropsychiatric diagnosis and management of chronic sequelae of war-related mild to moderate traumatic brain injury. Journal of rehabilitation research and development. 2009;46(6):757-796.

45. Brenner LA, Vanderploeg RD, Terrio H. Assessment and diagnosis of mild traumatic brain injury, posttraumatic stress disorder, and other polytrauma conditions: burden of adversity hypothesis. Rehabil Psychol. 2009;54(3):239-246.

46. Sigford BJ. "To Care for Him Who Shall Have Borne the Battle and for His Widow and His Orphan" (Abraham Lincoln): The Department of Veterans Affairs Polytrauma System of Care. Archives of physical medicine and rehabilitation. 2008;89(1):160-162.

47. Strasser DC, Uomoto JM, Smits SJ. The Interdisciplinary Team and Polytrauma Rehabilitation: Prescription for Partnership. Archives of physical medicine and rehabilitation. 2008;89(1):179-181.

48. Lew HL, Guillory SB, Cifu DX. Program development and defining characteristics of returning military in a VA Polytrauma Network Site. Journal of rehabilitation research and development. 2007;44(7):1027.

49. Dillman DA. Mail and internet surveys: The tailored design method. Vol 2: Wiley New York; 2000.

50. IBM SPSS Statistics for Windows [computer program]. Version 20. Armonk, NY: IBM Corp; 2011. 
51. NVivo qualitative data analysis software [computer program]. Version 10: QSR International Pty Ltd; 2012.

52. Miles MB, Huberman AM. Qualitative data analysis: An expanded sourcebook. Sage; 1994.

53. Ellison ML, Mueller L, Smelson D, et al. Supporting the education goals of post-9/11 veterans with self-reported PTSD symptoms: a needs assessment. Psychiatric rehabilitation journal. 2012;35(3):209-217.

54. Smith-Osborne A. Supported education for returning veterans with PTSD and other mental disorders. Journal of Rehabilitation. 2012;78(2):4.

55. Lew HL, Otis JD, Tun C, Kerns RD, Clark ME, Cifu DX. Prevalence of chronic pain, posttraumatic stress disorder, and persistent postconcussive symptoms in OIF/OEF veterans: polytrauma clinical triad. Journal of rehabilitation research and development. 2009;46(6):697-702.

56. Becker DR, Baker SR, Carlson L, et al. Critical strategies for implementing supported employment. Journal of Vocational Rehabilitation. 2007;27(1):13-20.

57. Bond GR, Peterson AE, Becker DR, Drake RE. Validation of the Revised Individual Placement and Support Fidelity Scale (IPS-25). Psychiatric services. 2012;63(8):758763.

58. Davis LL, Leon AC, Toscano R, et al. A randomized controlled trial of supported employment among veterans with posttraumatic stress disorder. Psychiatric services. 2012;63(5):464-470. 
510 59. Ottomanelli L, Goetz LL, Suris A, et al. Effectiveness of supported employment for 511 veterans with spinal cord injuries: results from a randomized multisite study. Archives of physical medicine and rehabilitation. 2012;93(5):740-747. 
Table 1. Supervisor and vocational rehabilitation specialist experiences with providing SE to Veterans with TBI history, by site type.

\section{Site Type}

p-value or

Fisher's

\begin{tabular}{lllll} 
& & Pilot & \multicolumn{1}{c}{ Non-pilot } & Exact Test \\
\hline SE Supervisors & \multicolumn{1}{c}{$\mathbf{N = 5}$} & \multicolumn{1}{c}{$\mathbf{N = 4 9}$} & \\
\hline $\begin{array}{l}\text { SE provided to Veterans with TBI } \\
\text { history }\end{array}$ & $\begin{array}{c}100 \% \\
(\mathrm{n}=5)\end{array}$ & $\begin{array}{l}59.2 \% \\
(\mathrm{n}=29)\end{array}$ & .09
\end{tabular}

Time working with SE program
$<5$ years
$40.0 \%$
$57.1 \%$
$(\mathrm{n}=2)$
$(\mathrm{n}=28)$
$>5$ years
$60.0 \%$
$42.9 \%$
$(\mathrm{n}=3)$
$(\mathrm{n}=21)$

SE vocational rehabilitation specialist FTEE dedicated to Veterans with TBI history

Current

$$
\begin{aligned}
& .70 \pm .45(0-1) \quad .76 \pm .87(0-4) \\
& \text { ( } \mathrm{n}=46)
\end{aligned}
$$

Ideal

$$
1.80 \pm .45(1-2)
$$

$1.67 \pm .93(.25-5)$

$(\mathrm{n}=5)$ $(\mathrm{n}=46)$

\section{SE Vocational Rehabilitation \\ Specialists}

$\mathbf{N}=\mathbf{9}$

$N=56$

Time working with SE program

$<5$ years

$$
33.3 \%
$$

25

5 years

$(\mathrm{n}=3)$

$51.8 \%$

$(\mathrm{n}=29)$

$66.7 \%$

$48.2 \%$

$(\mathrm{n}=6)$

$(\mathrm{n}=27)$

Providing SE to Veterans with TBI history compared to other conditions

About the same to much easier

$$
\begin{array}{ll}
55.6 \% & 44.6 \% \\
(\mathrm{n}=5) & (\mathrm{n}=25)
\end{array}
$$

Somewhat to much more

$44.4 \%$

$55.4 \%$

difficult

$(\mathrm{n}=4)$

$(\mathrm{n}=31)$

Worked with polytrauma/TBI clinic

$77.8 \%$

$53.8 \%$ 
team

$$
(\mathrm{n}=7)
$$

$(\mathrm{n}=21 / 39)^{*}$

Communication frequency with

$3.86 \pm 1.35(2-6)$

$1.86 \pm 1.46(0-6) \quad 0.003$

polytrauma/TBI clinic team about SE

$(\mathrm{n}=7)$

$(\mathrm{n}=22 / 39)$

referrals

Perceived helpfulness in working with

polytrauma/TBI clinic team ${ }^{\ddagger}$

$4.29 \pm 1.11(2-5)$

$3.27 \pm 1.45(0-5)$

$(n=22 / 39)$

Note. Values are mean \pm SD (range) or as otherwise indicated.

*Denominator is reduced after Polytrauma Point of Contact sites indicate they have no

polytrauma/TBI clinic team. One Polytrauma Point of Contact site did not respond. All pilot sites had a polytrauma/TBI clinic team.

${ }^{\dagger} 0$ (Never) to 7 (Daily or almost daily)

${ }^{\ddagger} 1$ (Not at all) to 5 (Extremely) 
Table 2. SE supervisor responses to which disciplines would be helpful to better support the vocational rehabilitation needs of Veterans with TBI history.

\section{Ideal Team (ranked by frequency of response)}

1. Peer support specialists

2. Case managers/social workers

3. Job developers (separate from vocational rehabilitation specialists)

4. Mental/behavioral health professionals (e.g., psychologist, neuropsychologist, psychiatrist, substance abuse counselor)

5. Medical providers (e.g., physician, physician assistant, nurse)

6. Other rehabilitation staff (e.g., occupational therapists, recreational therapists, and speechlanguage pathologists) 
1 Table 3. SE supervisor suggestions for program improvement

\section{Suggestion $\quad$ Exemplar Quotes}

1. Increase SE $\quad \bullet \quad$ "To have a VRS/VRC staff dedicated to, or embedded in supporting Staffing the Polytrauma/TBI program providing SE services. Currently only providing CWT/SE to Veterans with SMI." (Non-pilot)

2. Add vocational rehabilitation as part of rehabilitation treatment plan

3. Base SE eligibility on employment
- "Most often active Polytrauma cases are staffed and discussed in a very 'medical/acute rehab' manner. Vocational rehabilitation is seen as a tertiary referral that often comes just prior to discharge from other Polytrauma services. This delay in referral and focus on vocational rehabilitation also results in veterans feeling that vocational options are not part of their future planning, and also allows complacency and/or a focus/mindset on 'obtaining/ maintaining disability benefits' to set in." (Non-pilot)

- "To be effective, the SE program has to be an active participant in the Psychosocial Rehab Treatment Team. This provides the best wrap around services possible." (Non-pilot)

- $\quad$ "SE needs to be expanded to vets with TBI and PTSD, beyond the $25 \%$ rule. This would be invaluable to our program. We often refer [veterans with] PTSD \& TBI for voc[ational] assistance and they 
support needs, not diagnosis receive less intensive services than is needed because we can't fit them in the $25 \%$ SE. Flexibility to assess Veteran service needs based on functional capacity and support needs, rather than diagnosis, is better service for veterans. (Pilot)
4. Continuing education considered as part of the vocational rehabilitation

process
- $\quad$ "Integration of VBA [Veterans Business Administration] Chapter 31 Voc[ational] Rehab Counselors to the VHA TBI Team. We have a lot of veterans with TBI who are younger compared to our other SE (SMI) population and a significant number of them have SC [service-connected] disability. As such, they are interested in obtaining the necessary education to develop a career." (Non-pilot)

- Please avoid 'just get then a job syndrome'; focus on careers, education, and training. DO NOT let these veterans squander their GI bill benefits or Chapter 31 when they have the ability to go to school. TSES needs to know that education and training are of equal value to employment and result in better jobs and life quality. Let TSES/CWT programs support education as well as employment. (Pilot) 
1 Table 4. SE vocational rehabilitation specialist experiences with, and suggestions for, providing

2 SE to Veterans with TBI history.

\section{Experience}

Exemplar Quotes

\section{Challenging health and functional characteristics of Veterans with TBI}

Cognition and

Behavior

\section{Stakeholder support}

A. Facilitators

- "Support by VA administration regarding schedule and resources to provide services to [the TBI] population, weekly [staff meetings] and on-site trainings also assist with providing services to [the TBI] population." (Pilot)

- "Clinicians who have recognized and diagnosed TBI in Veterans, 
access to on-line training and information, team approach to service provision, quality case management, good family and peer support, motivation on the Veterans' part, understanding employers." (Nonpilot)

- "Great relationships with some employers that are willing to employ and monitor this population of Veterans." (Non-pilot)

B. Barriers

- More restrictions from management and other clinics that are clueless in the realities of job placement of this population diminish the SE VRS from being more effective (Non-pilot)

- There is a great potential to provide a breadth of SE Services to Veterans [with TBI] at this VA [medical center]. The CWT management are not interested in the CWT/SE program growing beyond what it already is. (Pilot)

\section{Integration of the SE and TBI clinical teams}

A. Facilitators

- "Our polytrauma team is very engaged in seeking positive outcomes for each of the Veterans they serve - this shows in my interactions with them. We have one of our SE specialists assigned to the polytrauma weekly meetings.... I can send messages or speak directly when needed and am confident in getting a great response 
(Non-pilot)

- "The communication and integration that the SE services have with treatment team which consist of case managers and a combination of psychiatrist, psychologist and or physician has really made the outcome successful.” (Non-pilot)

B. Barriers

- "They [TBI clinic providers] did not understand the SE model and the send inappropriate referrals. (Non-pilot)

- "Many of the polytrauma staff hold the belief that competitive employment is not a realistic goal for patients with TBI. Furthermore, they are not quick to follow evidence-based practice and refer for employment services when a patient expresses an interest; they wait for the patient 'to be ready."' (Pilot)

\section{Education and training on $\mathrm{SE}$ and post-TBI symptoms}

A. Facilitators

- "SE staff at this VA has been provided direct SE training from our mentor training VA site; we have been provided books, access to websites, therapeutic email workgroup, professional publications, etc.; and professional training seminars." (Non-pilot)|

- "Several trainings yearly, to include national level training for SE 
staff, local SE trainings, webinars, and continued monthly staffings and in-services to emphasize EBSE [evidence-based SE] practices." (Pilot)

B. Barriers

- "I believe the Polytrauma/TBI program could benefit from further education on EBSE [evidence-based supported employment] practices and success stories to further encourage involvement and integration with SE." (Pilot)

- "I would like more training and education regarding TBI so that I am more prepared when employers talk with me about the TBI as well as the potential benefits/concerns." (Non-Pilot)

\section{Suggestions for SE program improvement for Veterans with TBI}

Case management and Resources
- "SE staff can't provide 'case management' however that's exactly what many of our Vets need to gain/retain employment." (Nonpilot) 